
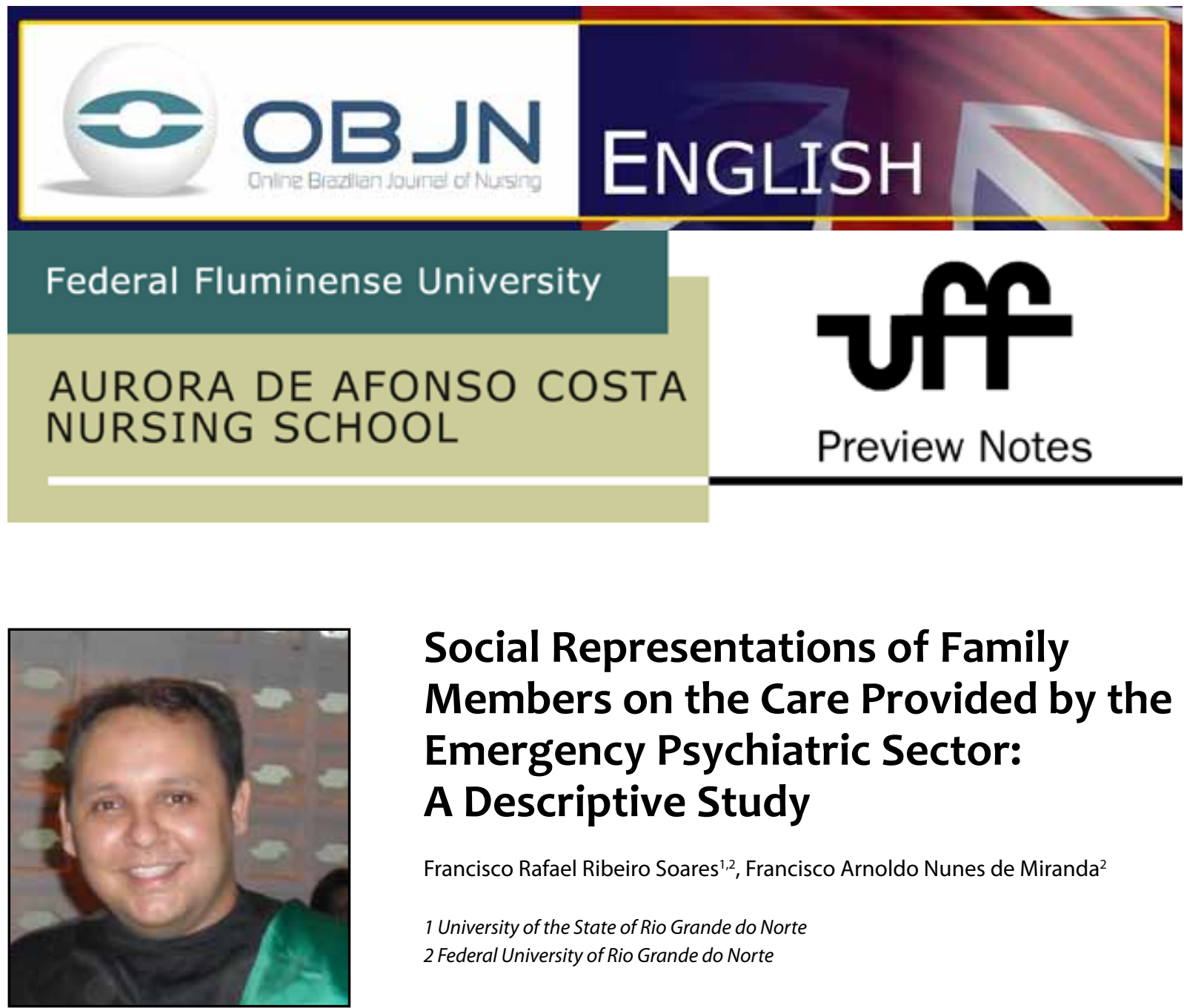

\title{
Social Representations of Family Members on the Care Provided by the Emergency Psychiatric Sector: A Descriptive Study
}

\author{
Francisco Rafael Ribeiro Soares ${ }^{1,2}$, Francisco Arnoldo Nunes de Miranda ${ }^{2}$ \\ 1 University of the State of Rio Grande do Norte \\ 2 Federal University of Rio Grande do Norte
}

\section{ABSTRACT}

Aim: To analyze the social representations of family members of patients who suffer from mental and behavioral problems regarding the care of emergency psychiatric disorders. Method: This is an exploratory and descriptive study, in which a qualitative approach based on Social Representations Theory (SRT) was used in addition to the use of multi-methods for data collection (semi-structured interviews and the free association of words technique). The software Analyse Lexicale par Contexte d'un Ensemble de Segments de Texte (ALCESTE) and thematic content analysis were used. The study scenario includes two mental health services in the municipality of Mossoró/RN involving the primary caregivers of the mental health patient and who have witnessed at least one situation characterized as being a crisis or involving a psychiatric emergency.

Descriptors: Mental Health; Psychiatric Services, Emergency; Nursing.

Soares FRR, Miranda FAN.Social representations of family members on the care provided by the emergency psychiatric sector: a descriptive study [internet] 2014 Oct [cited year month day]; 13 (suppl I): 461-3. Available from: http://www.objnursing.uff. br/index.php/nursing/article/view/5068 


\section{PROBLEM SITUATION AND ITS SIGNIFICANCE}

The reformist movements in the health arena (specifically in the field of mental and psychiatry health) have identified issues, among which can be highlighted the prioritization of the production of mental health care outside the mental hospital environment, focusing on goals such as reducing the demand for psychiatric beds, greater control over hospitalization, family co-participation and the improvement in the spirit of citizenship on the part of the social actors involved ${ }^{(1)}$.

The process of deinstitutionalization of users with regard to mental and behavioral disorders and their return to social life, have brought new challenges to the system. There is a growing demand for substitute services, which is also affected by a major global trend in psychiatry, where items once considered common in everyday life have begun to be objects requiring psychiatric intervention ${ }^{(2)}$.

After the implementation of the provisions of the Brazilian Psychiatric Reform and the substitutive services to the mental institution centered model, the focus of mental health care has ceased to be based exclusively on the mental disorder patient, and has also begun to encompass his family and community in a clear psychosocial perspective. Such individuals are recognized as agents of care, to be included in the therapeutic project and invited to effectively participate in the treatment of the patient, due to their unique role in the social reintegration of the patient ${ }^{(3)}$.

The process of deinstitutionalization of the patient in psychiatric distress demands a continuous learning process on the part of health professionals and families, since the families live most of the time with the patient. Thus, knowledge in terms of behavioral and mental illness, and the way in which they deal with their family member who is going through a crisis situation, becomes very relevant.

\section{GUIDING QUESTION}

What are the social representations built by family members of individuals suffering from mental and behavioral disorders, regarding the care provided with regard to psychiatric emergencies in the district of Mossoró/RN?

\section{AIMS \\ General \\ To analyze the social representations of fam- ily members of patients who are suffering from psychological and behavioral dysfunctions in terms of the psychiatric emergency care provision in Mossoró.}

\section{Specifics}

To describe the contents of the social representations of relatives of patients with regard to psychiatric emergency care;

To characterize the heuristic and iconic aspects present in the social representations of family members with regard to such care.

\section{METHOD}

This is an exploratory and descriptive study, in which a qualitative approach based on the Social Representations Theory (SRT) was used.

It is understood that SRT, in terms of its heuristic and iconic aspects, arises from interpersonal relationships in line with individual experiences, which create a consensual universe in the reification interface of science on the care of the psychiatric emergencies in the context under consideration, bringing up the senses and meanings of the actors involved, especially the family ones, as the focus of this study. 
The research scenarios are two specific services in the city of Mossoró: an outpatient mental health care unit and a psychiatric hospital. The sample will consist of the main family caregivers of individuals in situations of mental or behavioral disorder who have witnessed a situation characterized as being a psychiatric emergency and its care. The number of 73 people was determined in order to provide a sample with a confidence level of 95 percent and an error margin of $10 \%$. Inclusion criteria: individuals over 18 years of age who have a degree of consanguineous kinship or affinity with users who suffer from mental and behavioral disorders, who have witnessed any crisis situation involving the provision of care by the Mobile Emergency Care Service (SAMU) or other means, and the removal of the patient to the psychiatric hospital, general emergency room or other health services. Individuals who have a clinical disease that alters perception and memory were excluded.

We opted for two instruments for data collection: a script for applying the Technique of Free Association ofWords (TFAW) and a semi-structured interview script. The survey data will be analyzed from the theoretical perspective of social representations, using the technique of thematic content analysis with the informational support of software entitled Analyse Lexicale par Contexte d'un Ensemble de Segments de Texte (ALCESTE).

The ethical aspects of the research were respected according to CNS Resolution No.466/2012, according to the protocol submitted to the Committee for Research Ethics of the UERN, and was approved under No. 748 109. Data were collected during September and October 2014.

\section{REFERENCES}

1. Elias ADS, Tavares CMM, Cortez EA. Nursing care to psychiatric patients in general emergency: sociopoetic inspiration. Online braz j nurs [internet]. 2012 [cited 2014 sept 24]; 11(Suppl 1):424-7. Available from: http://www.objnursing.uff.br/index.php/ nursing/article/view/3606

2. Soares FRR, Miranda FAN, Medeiros SM. Contextual analysis of the care of psychiatric emergencies. Rev enferm UFPE on line [internet]. 2013 [cited 2014 sept 24] 7(spe):4269-76. Available from: http://www. revista.ufpe.br/revistaenfermagem/index.php/ revista/article/view/4350/pdf_2658

3. Santos AFO, Cardoso CL. Autopercepção do estresse em cuidadores de pessoa em sofrimento mental. Psicol estud [internet]. 2012 [cited 2014 sept 24] 17(1):93-101. Available from: http://www.scielo.br/ pdf/pe/v17n1/v17n1a10.pdf

Francisco Rafael Ribeiro Soares - conception, drawing, writing, critical revision and final approval;

Francisco Arnoldo Nunes de Miranda - conception, drawing, writing, critical revision and final approval.

All authors participated in the phases of this publication in one or more of the following steps, in According to the recommendations of the International Committee of Medical Journal Editors (ICMJE, 2013): (a) substantial involvement in the planning or preparation of the manuscript or in the collection, analysis or interpretation of data; (b) preparation of the manuscript or conducting critical revision of intellectual content; (c) approval of the versión submitted of this manuscript. All authors declare for the appropriate purposes that the responsibilities related to all aspects of the manuscript submitted to OBJN are yours. They ensure that issues related to the accuracy or integrity of any part of the article were properly investigated and resolved. Therefore, they exempt the OBJN of any participation whatsoever in any imbroglios concerning the content under consideration. All authors declare that they have no conflict of interest of financial or personal nature concerning this manuscript which may influence the writing and/or interpretation of the findings. This statement has been digitally signed by all authors as recommended by the ICMJE, whose model is available in http://www. objnursing.uff.br/normas/DUDE_eng_13-06-2013.pdf

Received: 09/25/2014

Revised: $10 / 23 / 2014$

Approved: $10 / 23 / 2014$ 